\title{
Rational Design, Exploratory Synthesis and Lanthanide Emission Efficiency Comparison of Lanthanide(III)-cored Complexes Based on Naphthalene Acid Ligands for Efficient Energy Transfer Pathways
}

\author{
Nam Seob Baek. Yong Hee Kim, and Hwan Kyu Kim* \\ Center for Smart Light-Harvesting Materials and Department of Advanced Materials \\ Hannam University, Daejeon 306-791, Korea. "E-mail: hwankkim@mail.hannam.ac.kr \\ Received Augtst 7, 2006
}

Key Words : Naphthalene acid, Lanthanide complexes, Near-infrared emission, Energy transter process

The development of luminescent lanthanide complexes has been attracted considerable attention because of a wide variety of applications, such as planar waveguide amplifiers, ${ }^{1}$ light-emitting diodes, ${ }^{2}$ and MRI contrast agent. ${ }^{3}$ The complexation of luminescent $\mathrm{Ln}^{31}$ ion with organic ligand can lead to a system capable of overcoming intrinsically low molar absorption coefficients (typically $1-10 \mathrm{M}^{-1} \mathrm{~cm}^{-1}$ ) of $\mathrm{Ln}^{3 !}$ ions and effectively transferring excited energy from the light-absorbing ligand to central $\mathrm{Ln}^{3 /}$ ion. This sensitjzation process is much more effective than the direct excitation of $\mathrm{Ln}^{31}$ ions. ${ }^{4}$ To date, it is well-believed that only energy transfer from the triplet state of luminescent ligands to $\mathrm{Ln}^{31}$ ion is the most dominant mechanism. Therefore, most researches toward lanthanide ion sensitizers have been focused on developing the luminescent ligands with a triplet state matching the receiving lanthanide ion energy levels. Interestingly, however, several reports mentioned the energy transfer from the excited singlet state to $\mathrm{Ln}^{35}$ ion. ${ }^{6}$ Very recently, we also reported all possible ET pathways using Ptporphyrin (ETt) ${ }^{7}$ and anthracene ligand (ETs), ${ }^{8}$ and additionally, demonstrated the unusual ET pathway through the intramolecular charge transfer (ICT) state of the naphthalene ligand to $\mathrm{Ln}^{3 /}$ ion (ETc) for the first time (see Scheme 1). ${ }^{9}$ For finding out the most dominant ET pathway toward the highly efficient $\mathrm{Ln}^{31}$ emission, the $\mathrm{Ln}^{31}$ emission efficiency comparison for all three ET pathways should necessarily be explored under similar ET conditions.

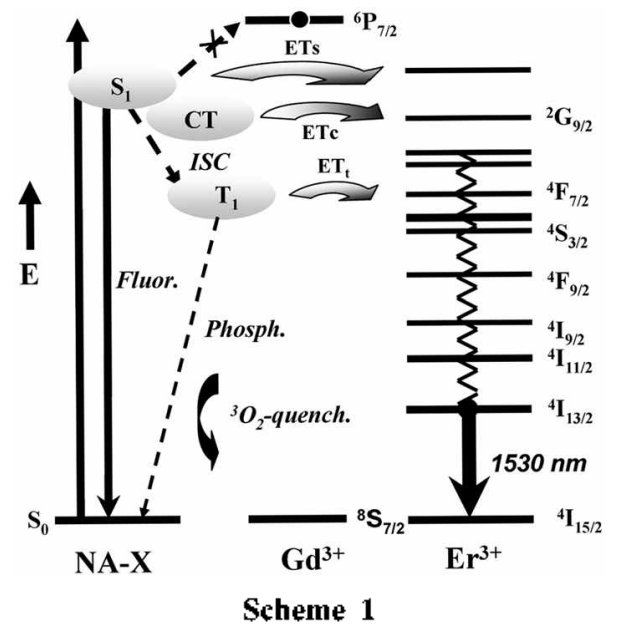

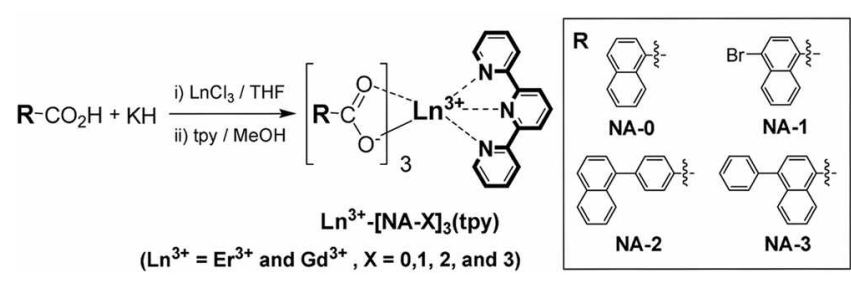

Scheme 2. Synthesis and chemical structures of lanthanide(III)cored complexes based on naphthalene acid ligands.

Here, to investigate all three possible ET pathways and compare the lanthanide emission efficiency for the various ET pathways in Er(III)-cored complexes, we have rationally designed and synthesized the structurally and UV-absorbingly similar ligands of 1-naphthoic acid (NA-0), 4-bromo4-naphthalen-1-yl-benzoic acid (NA-1), 4-naphthalen-1-ylbenzoic acid (NA-2) and 4-phenyl-naphthalene-1-carboxylic acid ligand (NA-3) and their stable 9-coordinated $\operatorname{Ln}(\mathrm{III})$ complexes (Scheme 2) (see Supporting Information). ${ }^{10}$

The nature of excited states of all four ligands was investigated by measuring the absorption and fluorescence spectra in various solvents (see Figure S4). In the previous report, we reported the large Stokes' shifted emission of NA-2 in polar solvent which is due to the formation of an ICT state in the excited state. We could not observe the phosphorescence even in the Gd(III) complex based on NA-2. These results indicate that the ISC process is not dominant in NA-2 and the energy transfer takes places from the ICT state to $\mathrm{Ln}^{3}$ jon in the Er(III) complex based on NA-2.9

On the other hand, our photophysical results suggest that the Ln(III) complexes based on NA-0 and NA-1 ligands have the ET mechanism via the excited triplet state (see Figure \$5-\$7). Bromine-substituted NA-1 ligand, as compared with NA-0 ligand, increases the rate of intersystem crossing (ISC) and decreases the fluorescence quantum yield, due to the internal heavy atom effect. ${ }^{12}$ The luminescence spectra of $\mathrm{Gd}^{31}-[\mathrm{NA}-0]_{3}$ (tpy) and $\mathrm{Gd}^{35}-[\mathrm{NA}-1]_{3}$ (tpy) in deoxygenated $\mathrm{m}-\mathrm{THF}$ at $77 \mathrm{~K}$ exhibit a strong phosphorescence band in the green region (see Figure S5). The phosphorescence lifetime was reduced from $50 \mu \mathrm{s}$ for $\mathrm{Gd}^{35}$ [NA-1] $]_{3}$ (tpy) to $20 \mu$ s for E* '-[NA-1] 3 (tpy) (see Figure $\$$ 6). These results provide the direct evidence of an energy transfer from the triplet state of the ligand to the $\mathrm{Er}^{3 /}$ ion. It 
Table 1. Photophysical properties of naphthalene-typed ligands and their Er(III) complexes

\begin{tabular}{|c|c|c|c|c|c|}
\hline & \multirow{2}{*}{$\frac{\mathrm{UV}}{\lambda_{\max }}$} & \multirow[b]{2}{*}{$\phi^{a}$} & \multicolumn{2}{|c|}{ Lifetime ( $/$ ss) } & \multirow{2}{*}{$-\left(\times 10^{-4}\right)$} \\
\hline & & & $\tau_{\rho}^{b}$ & $\tau_{\mathrm{obs}}{ }^{c}$ & \\
\hline $\mathrm{Gd}^{\hat{3}^{-}}-[\mathrm{NA}-0]:$ (tpy) & 303 & - & 20 & - & - \\
\hline $\mathrm{Er}^{3-}-[\mathrm{NA}-0] ;($ tpy $)$ & 303 & $0.034(0.11)$ & ND & $2.13(1.91)$ & 2.7 \\
\hline $\mathrm{Gd}^{3-}-[\mathrm{NA}-1] ;$ (tpy) & 305 & - & 50 & - & - \\
\hline $\mathrm{Er}^{2-}-[\mathrm{NA}-1] ;($ tpy $)$ & 305 & $0.0037(0.0038)$ & 20 & $2.22(1.71)$ & 2.8 \\
\hline $\mathrm{Er}^{2}-[\mathrm{NA}-2]$; $(\mathrm{tpy})$ & 298 & - & ND & $\mathrm{ND}(1.12)$ & - \\
\hline $\mathrm{Er}^{2}-[\mathrm{NA}-3] ;(\mathrm{tpy})$ & 314 & $0.056(0.15)$ & ND & $1.97(1.38)$ & 2.5 \\
\hline
\end{tabular}

"2-aminopyridme as a standard with $0=0.60$ in $1 \mathrm{~N} \mathrm{H}_{2} \mathrm{SO}_{4}{ }^{\prime \prime}$ (quanium vield of ligand in parentheses). " $\lambda_{\mathrm{en}}=520 \mathrm{~nm}$ in degassed chlorobenzene. ${ }^{c} \lambda_{\text {em }}=1530 \mathrm{~nm}$ (lifetime of $\mathrm{Er}$ ion in solid state is given in parentheses). ${ }^{d}$ Calculated from $\phi_{\mathrm{n}}=\tau_{\mathrm{c} b s} / \tau_{\mathrm{R}}$, where the radiative lifetimes were taken from the literature, with lypical lifelimes of $8 \mathrm{~ms}$ for $\mathrm{Er}^{3+}$ ion. $\mathrm{ND}$ : Nol detected.

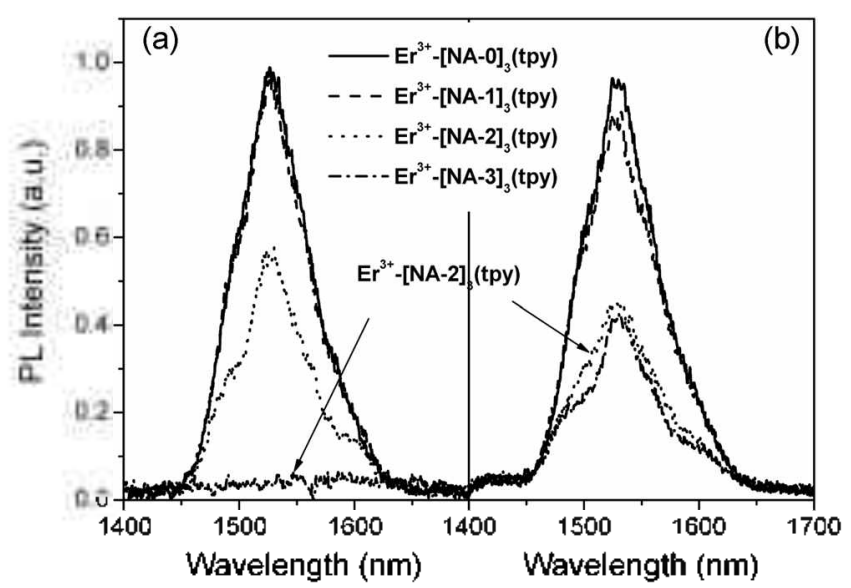

Figure 1. Emission spectra of the $\mathrm{Er}^{\mathrm{i}}{ }^{-}-[\mathrm{NA}-\mathrm{X}]_{3}$ (tpy) in degassed chlorobenzene $\left(a, \lambda_{e x}=300 \mathrm{nun}\right)$ and solid state $\left(b, \lambda_{e x}=350 \mathrm{nun}\right)$. The NIR ennission intensity has been corrected by the sample absorbance.

may be additionally supported from Er(III) luminescence quenching by oxygen (see Figure S7). ${ }^{13}$

Obviously, no detectable phosphorescence and no significant spectral dependence of NA-3 on the solvent polarity support the energy transfer from the singlet state of NA-3 ligand to central $\mathrm{Er}^{3+}$ ion taking place in $\mathrm{Er}^{3+}-[\mathrm{NA}-3]_{3}$ (tpy). ${ }^{8}$

The strong decrease of fluorescence or phosphorescence intensity of the complexed ligands is accompanied by enhancing the near infrared (NIR) emission of $\mathrm{Er}^{3+}$ ion, from the 4f-4f electronic transition of ${ }^{4} \mathrm{I}_{13 / 2}$ to ${ }^{-1} \mathrm{I}_{15 / 2}$, at $1530 \mathrm{~nm}$. Figure 1 can give a comparison for the NIR emission intensity of Er(III) complexes in three ET pathways. Most of $\mathrm{Er}$ (III) complexes, except for $\left.\mathrm{Es}^{3+}-[\mathrm{NA}-2]\right]_{3}$ (tpy), have no spectral dependence on solvent polarity and exhibit the strong NIR emission at $1530 \mathrm{~nm}$ in a degassed chlorobenzene solution and a solid state. The $\mathrm{Er}^{3-1}-[\mathrm{NA}-2]_{3}$ (tpy) exhibits no sensitized emission in chlorobenzene, but, a strong NR emission in DMSO. It reflects that the energy transfer pathway through the ICT state (see Figure S7). ${ }^{\circ}$ A series of Er(III) complexes exhibits the NIR emission with the following order: $\mathrm{Er}^{3+}-[\mathrm{NA}-1]_{3}(\mathrm{tpy})=\mathrm{Er}^{3+}-[\mathrm{NA}-0]_{3}$ (tpy) (via $\mathrm{ETt})>\mathrm{Er}^{3+}-[\mathrm{NA}-3]_{3}$ (tpy) (via $\left.\mathrm{ETs}\right) \geq \mathrm{Er}^{3+}-[\mathrm{NA}-2]_{3}$ (tpy) (via Etc).

In summary, to elucidate ET efficiency comparison for all three ET pathways toward the efficient $\mathrm{Ln}^{3+}$ emission, the design and synthesis of structurally and photophysically similar Er(III) complexes have been investigated for the first time. Although ET process via the triplet state to $\mathrm{Ln}^{31}$ ion is considered as main efficient ET pathway in Ln(III) complex, this sensitization process is not strongly dominated on $\mathrm{Ln}^{3+}$ emission, compared with other ET pathways via singlet or charge transfer state. Surprisingly, the ISC process caused by the heavy $\mathrm{Ln}^{3+}$ ion effect in Ln(III) complexes is not dominant process over the ICT or the radiative relaxation process and the ET process via the triplet state to $\mathrm{Ln}^{31}$ ion is not strongly dominated on $\mathrm{Ln}^{3+}$ emission, compared with other ET pathways via singlet or charge transfer state. As concluded, no matter which ET pathway takes place, the key factor for strong lanthanide emission is the ET efficiency between the organic ligand and $\mathrm{Ln}^{3+}$ ion, associated with the quantum yield of a ligand and a proper $J$ value. This study can provide the criteria for designing the ligand to achieve efficient $\mathrm{Ln}^{3+}$ emission.

Acknowledgment. This research work was financially supported from the Korea Ministry of Science and Technology (MOST) and KOSEF through National Research Laboratory Program at Hannam University.

Supporting Information Available: Experimental procedures for the synthesis of the ligands and their complexes and spectroscopic data (PDF). This material is available via http://ww:kscnet.or.kr/bkcs.

\section{References and Notes}

I. Kim, H. K.; Oh, J. B.; Baek, N. S.; Roh, S.-G.; Nah, M.-K.; Kim, Y. H. Bull. Kor. Chem. Soc. 2005, 26(2), 201.

2. Oyamada, T.; Kawamura, Y.; Koyama, T.; Sasabe, H.; Adachi, C. Adv, Mater, 2004, 16, 1082 .

3. Livramento, J. B.; Toth, E.; Sour, A.; Borel, A.; Merbach, A. E.; Rulofl, R. Angew, Chem. Int, Ed, 2006, 44, 1480.

4. Steemers, F. J.; Verboom, W;; Reinhoud, D. N.; van der Tol, E. B.; Verhoeven, J. W. J. Ani. Chem. Soc. 1995, II7, 9408.

5. Oude Wolbers, M. P.; van Veggel, F. C. J. M.; Snellink-Ruel, B. H. M.; Hofstraat, J. W. Geurts, F. A. J.; Reinhoudt. D. N. J. Am. Chem. Soc. 1997, 119, 138 .

6. Hebbink, G A.; Klink, S. I.; Grave, L.; Alink, P. G. B. O.; van Veggel, F. C. J. M. ChemPhysChem, 2002, 3, 1014.

7. Oh, J. B.; Kim, Y. H.; Nah, M. K.; Kim, H. K. J. Lumin 2005, II, 255.

8. Baek, N. S.; Kim, Y. H.; Roh, S.-G.; Kwak, B. K.; Kim, H. K. $A d$. Funct, Mater. 2006, 16, 1873 .

9. Kim, Y. H.; Baek, N. S.; Kim, H. K. ChemPhysChem 2006, 7, 213.

10. Roh, S.-G.; Baek, N. S.; Hong, K.-S.; Kim, H. K. Bull, Kor. Chem. Soc. 2004, 25, 343.

11. Eaton, D. F. Pure Appl. Chem. 1988, 60, 1107.

12. Barltrop, J. A.; Coyle, J. D. Excited States in Organic Chemistry; John Wiley \& Sons: Inc.: London, 1975; p 83.

13. Werts, M. H. V.; Hofstraal, J. W.; Geurts, F. A. J.; Verhoeven, J. W. Chem. Phys, Lett. 1997, 276, 196. 